\title{
OPTIMASI METODE EKSTRAKSI KUERSETIN DARI DAUN KELOR (Moringa oleifera L.)
}

\author{
N. P. L. Laksmiani", I W. A. Widiantara, K. D. Adnyani , A. B. S. Pawarrangan \\ Program Studi Farmasi, Fakultas Matematika dan Ilmu Pengetahan Alam, Universitas Udayana, \\ Bukit Jimbaran, Badung, Bali \\ Laboratorium Analisis Program Studi Farmasi, Fakultas Matematika dan Ilmu Pengetahuan \\ Alam, Universitas Udayana, Bukit Jimbaran, Badung, Bali \\ *Email: lindalaksmiani@gmail.com
}

\begin{abstract}
ABSTRAK
Keberadaan tanaman kelor di Indonesia sangat berlimpah. Daun kelor merupakan sumber senyawa polifenol yaitu flavonoid. Salah satu flavonoid utama yang ditemukan pada daun kelor adalah kuersetin. Untuk dapat mengembangkan potensi kuersetin dari tanaman kelor, maka perlu dilakukan ekstraksi. Penelitian ini bertujuan untuk mengetahui metode ekstraksi yang paling optimal dalam mengekstraksi kuersetin dari daun kelor. Optimasi metode ekstraksi kuersein dari daun kelor dilakukan menggunakan metode maserasi, sokhletasi, dan refluks. Pelarut yang digunakan adalah metanol dengan penambahan $\mathrm{HCl}$ 1,2 N. Penetapan kadar kuersetin dalam ekstrak menggunakan metode KLT-densitometri yang tervalidasi. Rendemen yang paling besar dihasilkan dari metode ekstraksi maserasi yaitu sebesar 24,08 \% b/b. Ekstraksi dengan metode refluks dan sokhletasi menghasilkan rendemen berturut-turut $23,44 \%$ b/b dan $10,12 \% \mathrm{~b} / \mathrm{b}$. Analisis kualitatif adanya kuersetin pada ekstrak dilakukan dengan membandingkannya dengan nilai Rf standar kuersetin yaitu 0,4. Kadar kuersetin pada ekstrak hasil ekstraksi maserasi adalah yang paling besar yaitu sebanyak $24,45 \% \mathrm{~b} / \mathrm{b}$. Ekstraksi dengan metode sokhletasi menghasilkan kuersetin sebanyak 20,95\% b/b.
\end{abstract}

Kata kunci : kuersetin, daun kelor, metode ekstraksi, optimasi

\section{ABSTRACT}

Moringa plants is very abundant in Indonesia. Moringa leaves are a source of polyphenol compounds, namely flavonoids. One of the main flavonoids found in Moringa leaves is quercetin. To be able to increase the concentration of quercetin from moringa plants, extraction is necessary. This study aims to determine the most optimal extraction method in extracting quercetin from Moringa leaves. Optimization of quersein extraction methods from Moringa leaves was carried out using maceration, soxhletation, and reflux methods. The solvent used was methanol acidified with 1,2 N HCl. Determination of the concentration of quercetin in the extract used a validated TLC-densitometry method. The highest rendement obtained from the maceration extraction method was $24.08 \% \mathrm{w} / \mathrm{w}$. Extraction by reflux and sochletation methods yielded rendement of $23.44 \% \mathrm{w} / \mathrm{w}$ and 10.12 $\%$ w/w respectively. Qualitative analysis of quercetin in the extract was carried out by comparing its Rf value with the standard quercetin which is 0,4 . The quercetin level of the extract from maceration extraction was the highest, which was $24.45 \%$ w/w. Extraction using the soxhletation method obtained quercetin as much as 20.95 $\% \mathrm{w} / \mathrm{w}$.

Keywords: quercetin, Moringa oleifera leaves, extraction method, optimization

\section{PENDAHULUAN}

Kuersetin merupakan flavonoid yang diklasifikasikan ke dalam golongan flavonol yang paling berlimpah terkandung dalam buah-buahan dan sayuran (Wach et al., 2007). Kuersetin memiliki banyak manfaat bagi kesehatan diantaranya seperti antioksidan dengan menangkal radikal bebas, sariawan, efek neurologis, aktivitas antivirus, antiinflamasi, asma, aktivitas kardiovaskular, agen antikanker, antialergi, dan antimelanogenesis (Choi dan Shin, 2016; Kumar et al, 2017).

Kuersetin dapat ditemukan di berbagai produk makanan dan tanaman seperti buah- 
buahan, biji-bijian, sayuran, teh, dan kopi (Baghel et al., 2012). Kuersetin terdapat pada daun dan bagian lain pada tumbuhan dalam bentuk aglikon dan glikosida (Wach et al., 2007). Bentuk glikosida kuersetin yang paling umum ditemukan dalam berbagai buah dan sayuran adalah kuersetin 3-O-glikosida. Salah satu contoh turunan kuersetin 3-O-glikosida yang terikat dengan disakarida dan sering terdeteksi pada tanaman adalah rutin (3-Orhamnosylglucoside) (Materska, 2008).

Keberadaan tanaman kelor di Indonesia sangat berlimpah. Daun kelor merupakan salah satu jenis tanaman yang banyak dikonsumsi oleh orang Indonesia sebagai sayuran. Kelor memiliki nama latin Moringa oleifera L. dan termasuk ke dalam famili Moringaceae (Rahman, 2015). Daun kelor merupakan sumber senyawa polifenol seperti flavonoid dan asam fenolik. Flavonoid utama yang ditemukan pada daun kelor adalah myrecytin, kuersetin, dan kaempferol (Vergara-Jimenez et al, 2017).

Potensi kuersetin di dalam dunia kesehatan sangat banyak. Untuk dapat mengembangkan potensi kuersetin dari senyawa alam salah satunya tanaman kelor yang terdapat berlimpah di Indonesia, maka perlu dilakukan ekstraksi. Dengan ekstraksi, maka kuersetin akan dapat diambil dari daun kelor, sehingga dapat diteliti kadarnya dalam daun kelor tersebut, serta dapat dimanfaatkan lebih lanjut. Pengukuran kadar kuersetin pada daun kelor cukup penting dilakukan karena dapat digunakan untuk mengevaluasi banyaknya kuersetin yang dapat diekstaksi dari tanaman tersebut.

Ekstraksi kuersetin dari tanaman dapat dilakukan dengan berbagai metode. Pada penelitian ini ekstraksi kuersetin dari daun kelor dilakukan degan menggunakan tiga metode yang berbeda yaitu maserasi, sokhletasi, dan refluks. Perbandingan metode ekstraksi terhadap rendemen dan kandungan senyawa daun kelor telah dilakukan oleh Kiswandono (2011) dengan membandingkan metode ekstraksi maserasi dan refluks. Kedua ekstrak tersebut selanjutnya dilakukan uji skrining fitokimia. Variasi metode ekstraksi kuersetin dari daun kelor pada penelitian ini bertujuan untuk mengetahui metode ekstraksi mana yang paling optimal dalam mengekstraksi senyawa kuersetin dari daun kelor yang dianalisis secara kuantitatif.

\section{BAHAN DAN METODE}

\section{Bahan}

Bahan yang digunakan dalam penelitian ini adalah baku kuersetin, metanol, asam klorida, akuades, toluena, etil asetat, asam formiat, plat KLT silika gel GF254, daun kelor

Alat

Alat yang digunakan dalam penelitian ini adalah seperangkat alat sokhlet, seperangkat alat refluks, hotplate, termometer, kertas saring, rotary evaporator, neraca analitik, chamber, blender, ayakan 60 mesh, oven, autosampler, densitometer, dan alat-alat gelas yang biasa digunakan dalam laboratorium

\section{Metode Penelitian \\ Pembuatan Serbuk Daun Kelor}

Daun kelor dikumpulkan kemudian disortasi dan didapatkan daun kelor yang hijau dan dalam keadaan baik. Daun kelor dikeringkan dengan cara dikering-anginkan pada suhu ruang. Daun kelor yang sudah kering dihaluskan menggunakan blender. Serbuk daun kelor diayak menggunakan ayakan 60 mesh sehingga diperoleh serbuk daun kelor yang halus dan homogen.

\section{Ekstraksi dengan Metode Maserasi}

Serbuk daun kelor ditimbang sebanyak 25 gram dan dimasukkan ke dalam toples maserasi. Pelarut metanol sebanyak $500 \mathrm{~mL}$ dan $100 \mathrm{~mL} \mathrm{HCl} 1,2 \mathrm{~N}$ dituang ke dalam toples maserasi kemudian diaduk. Toples maserasi ditutup rapat dan dilapisi menggunakan aluminium foil kemudian dilakukan maserasi selama 1 hari. Setelah 1 hari, ekstrak disaring dan dilakukan remaserasi dengan pelarut metanol $250 \mathrm{~mL}$ dan $50 \mathrm{~mL}$ $\mathrm{HCl} 1,2 \mathrm{~N}$ selama 1 hari. Ekstrak yang diperoleh diuapkan pelarutnya dengan rotary evaporator dan oven sehingga didapatkan ekstrak kental.

\section{Ekstraksi dengan Metode Sokhletasi}

Serbuk daun kelor ditimbang sebanyak 25 gram. Alat sokletasi dipasang. Serbuk daun kelor dibungkus dengan kertas saring dan diikat dengan benang, kemudian dimasukkan ke selongsong pada alat sokhlet. Pelarut metanol sebanyak $500 \mathrm{~mL}$ dan $100 \mathrm{ml} \mathrm{HCl} \mathrm{1,2}$ $\mathrm{N}$ dimasukkan ke dalam labu alas bundar. Sokletasi dilakukan pada suhu $65^{\circ} \mathrm{C}$ selama 10 
jam sampai tetesan siklus tidak berwarna lagi. Ekstrak yang diperoleh diuapkan pelarutnya dengan rotary evaporator dan oven sehingga didapatkan ekstrak kental (Manasa et al., 2013).

\section{Ekstraksi dengan Metode Refluks}

Serbuk daun kelor ditimbang sebanyak 25 gram. Serbuk daun kelor direfluks dengan menggunakan pelarut metanol sebanyak 500 $\mathrm{mL}$ dan $100 \mathrm{ml} \mathrm{HCl} \mathrm{1,2} \mathrm{N.} \mathrm{Refluks} \mathrm{dilakukan}$ selama 14 jam pada suhu $90^{\circ} \mathrm{C}$. Hasil ekstraksi disaring dengan kertas saring. Ekstrak yang diperoleh diuapkan pelarutnya dengan rotary evaporator dan oven sehingga didapatkan ekstrak kental (Pakade et al., 2013).

\section{Penetapan Kadar Kuersetin}

Penetapan kadar kuersetin dilakukan dengan KLT-Densitometri. Digunakan plat KLT silika gel 60 GF254, kemudian plat dicuci dengan metanol dan diaktivasi pada suhu $110^{\circ} \mathrm{C}$ selama 15 menit. Larutan sampel dan standar kuersetin ditotolkan pada plat dengan volume penotolan sebanyak $10 \mu \mathrm{L}$ menggunakan autosampler. Plat dielusi pada chamber yang telah jenuh dengan fase gerak toluena: etil asetat: asam formiat $(5: 4: 0,2)$. Plat yang telah dielusi kemudian diamati di bawah sinar UV $254 \mathrm{~nm}$ dan UV $366 \mathrm{~nm}$. Plat discan dengan menggunakan densitometer pada panjang gelombang $265 \mathrm{~nm}$ (Doshi dan Une, 2016; Sudjarwo et al., 2019).

\section{HASIL DAN PEMBAHASAN}

Tahap pertama yang dilakukan adalah pembuatan serbuk daun kelor. Pengumpulan daun kelor dilakukan di daerah Bebandem, Karangasem. Daun kelor yang didapat kemudian disortasi dengan cara memisahkan daun yang kuning dan berbintik. Selain itu daun dipisahkan dari batang dan rantingranting kecil sehingga diperoleh daun kelor yang hijau dan dalam keadaan baik. Daun kelor dikeringkan dengan cara dikeringanginkan pada suhu ruang agar menghindari rusaknya zat aktif yang terkandung pada daun kelor (Luliana dkk., 2016). Serbuk daun kelor diayak menggunakan ayakan 60 mesh agar diperoleh serbuk yang halus dan homogen. Selain itu, dari proses pengayakan tersebut diharapkan agar rendemen ekstrak yang diperoleh bisa maksimal.
Ekstraksi kuersetin dari daun kelor dilakukan dengan menggunakan pelarut metanol karena sifatnya yang sangat larut dalam metanol dan dapat memberikan hasil ekstraksi yang terbaik (Dmitrienko et al., 2012; Kumar et al., 2017). Dalam sampel bahan alam, kuersetin tidak hanya terdapat dalam bentuk bebasnya, tetapi juga dalam bentuk terikat sebagai glikosida. Sehingga untuk memutus ikatan glikosida perlu dilakukan hidrolisis menggunakan asam. Pada penelitian ini, hidrolisis asam dilakukan dengan menggunakan $\mathrm{HCl}$ 1,2 N. Penambahan $\mathrm{HCl} 1,2 \mathrm{~N}$ secara efektif mengubah rutin menjadi kuersetin, sehingga konsentrasi kuersetin dalam sampel meningkat 2-50 kali setelah dihidrolisis menggunakan asam (Dmitrienko et al., 2012).

Perhitungan rendemen ekstrak kental dari ketiga metode ekstraksi dilakukan. Rendemen yang paling besar dihasilkan dari metode ekstraksi maserasi, kemudian disusul metode ekstraksi refluks, dan terakhir sokletasi. Metode maserasi menghasilkan ekstrak kental sebanyak 6,02 gram dengan rendemen sebesar 24,08\%. Metode refluks menghasilkan ekstrak kental sebanyak 5,86 gram dengan rendemen sebesar 23,44\%. Metode ekstraksi sokletasi menghasilkan ekstrak kental sebanyak 2,53 gram dengan rendemen sebesar $10,12 \%$.

Tahapan selanjutnya yaitu dilakukan identifikasi dan penetapan kadar kuersetin pada masing-masing ekstrak dengan metode KLT-Densitometri. Varisai konsentrasi larutan seri yang digunakan adalah 20, 40, 80, 160, dan 320 ppm. Larutan sampel masing-masing ekstrak dibuat dengan konsentrasi 1 gram $/ 5$ $\mathrm{mL}$. hasil pengukuran larutan seri menghasilkan persamaan regresi linier $\mathrm{y}=$ $1,3213 \mathrm{x}-24,0406$ dengan nilai $\mathrm{r}$ sebesar 0,99986 .

Hasil identifikasi plat yang terdapat pada panjang gelombang $254 \mathrm{~nm}$ didapatkan spot larutan standar kuersetin dengan $\mathrm{Rf}$ sebesar 0,4 , namun spot tersebut hanya terlihat pada larutan standar 5. Hasil pada panjang gelombang $366 \mathrm{~nm}$ didapatkan spot dengan $\mathrm{Rf}$ yang sama pada larutan seri 2 sampai 4 . Spot pada ekstrak juga menunjukkan Rf yang sama dengan larutan seri sehingga dapat disimpulkan ekstrak tersebut mengandung kuersetin secara kuantitatif. 


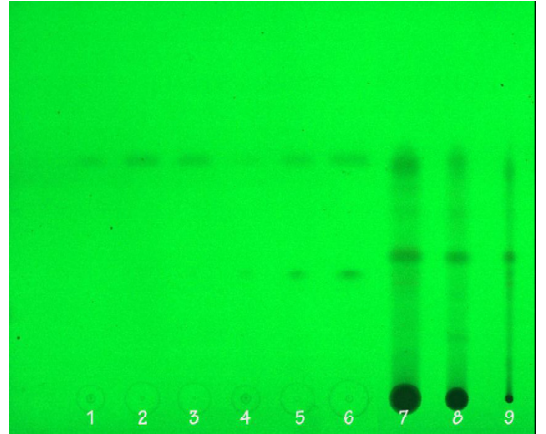

Gambar 1. Hasil Pemisahan Seri Kuersetin dan Sampel pada UV $254 \mathrm{~nm}$

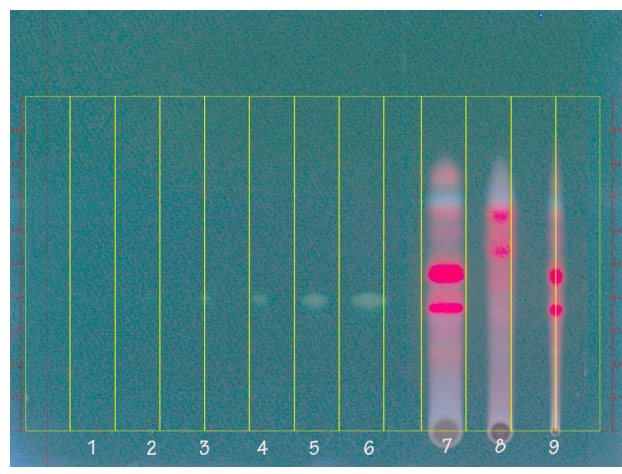

Gambar 2. Hasil Pemisahan Seri Kuersetin dan Sampel pada UV $366 \mathrm{~nm}$

Melalui nilai Rf diketahui bahwa ekstrak maserasi dan ekstrak sokletasi mengandung kuersetin sedangkan ekstrak refluks tidak mengandung kuersetin karena tidak terdapat spot yang memiliki nilai Rf sebesar 0,4. Kadar kuersetin pada ekstrak hasil ekstraksi maserasi sebanyak $24,45 \%$ b/b dan pada ekstraksi sokletasi didapatkan kuersetin sebanyak 20,95\% b/b.

\section{SIMPULAN}

Berdasakan hasil penelitian, rendemen ekstrak daun kelor yang paling besar diperoleh dengan metode ekstraksi maserasi yaitu sebesar 24,08 \%. Kadar kuersetin pada ekstrak hasil ekstraksi maserasi adalah yang paling besar yaitu sebanyak $24,45 \%$ b/b.

\section{UCAPAN TERIMA KASIH}

Penulis mengucapkan terima kasih kepada semua pihak yang telah membantu dan mendukung dalam menyelesaikan penelitian ini.

\section{DAFTAR PUSTAKA}

Baghel, S. S., Shrivastava, N., Baghel, R. S., Agrawal, P., dan Rajput, S. 2012. A Review of Quercetin: Antioxidant and Anticancer Properties. World Journal of Pharmacy and Pharmaceutical Sciences. 1 (1): 146-160.

Choi, M. dan Shin, H. 2016. AntiMelanogenesis Effect of Quercetin, Cosmetics. 3: 1-16.

Dmitrienko, S. G., Kudrinskaya, V. A., dan Apyari, V. V. 2012. Methods of Extraction, Preconcentration, and Determination of Quercetin. Journal of Analytical Chemistry. 67 (4): 299311.

Doshi, G. M. dan Une, H. D. 2016. Quantification of Quercetin and Rutin from Benincasa hispid aSeeds and Carissa Congesta Roots by Highperformance Thin Layer Chromatography and Highperformance Liquid Chromatography. Pharmacognosy Research. 8 (1): 3742.

Kumar, R., Vijayalakshmi, S., dan Nadanasabapathi, S. 2017. Health Benefits of Quercetin. Defence Life Science Journal. 2 (2): 142-151.

Luliana, S., Purwanti, N. U., dan Manihuruk, K. N. 2016. Pengaruh Cara Pengeringan Simplisia Daun Senggani (Melastoma malabathricum L.) Terhadap Aktivitas Antioksidan Menggunakan Metode DPPH (2,2difenil-1- pikrilhidrazil). Pharm Sci Res. 3 (3): 120-129.

Manasa, M., Kumar, S. M., dan Vangalapati, M. 2014. Modelling and purification of quercetin from skin of Allium cepa by soxhlet extractor. BTAIJ. 9 (6), 248-251.

Materska, M. 2008. Quercetin and Its Derivatives: Chemical Structure and Bioactivity - A Review. Polish Journal of Food and Nutrition Sciences. 58 (4): 407-413.

Pakade, V., Cukrowska, E., Lindahl, S., Turner, C., dan Chimuka, L. 2013. Molecular imprinted polymer for solid-phase extraction of flavonol aglycones from Moringa oleifera extracts J. Sep. Sci. 36, 548-555. 
Rahman, F. 2015. Efek Nefroproktektor Ekstrak Etanol Daun Kelor Terhadap Kerusakan Histologis Nefron Mencit Yang Diinduksi Parasetamol. Skripsi. Universistas Sebelas Maret. Surakarta.

Sudjarwo, Alfi, M. N., dan Annuryanti, F. 2019. Validation and Development of TLC-Densitometry Method for Standardization of Soursop Leaf Extract (Annona muricata Linn.) with Quercetin. IJPSR. 10(2): 686-691.
Vergara-Jimenez, M., Almatrafi, M. M., dan Fernandez, M. L. 2017. Bioactive Components in Moringa Oleifera Leaves Protect against Chronic Disease. Antioxidants. 6 (91): 1-13.

Wach, A., Pyrzyn'ska, K., dan Biesaga, M. 2007. Quercetin Content in Some Food and Herbal Samples. Food Chemistry. 100: 699-704. 